\title{
Colonoscopy in Obese Patients: Time to Change Position
}

\author{
Alfredo J. Lucendo
}

Received: 10 December 2012/Accepted: 19 December 2012/Published online: 12 January 2013

(C) Springer Science+Business Media New York 2013

Improvements in the diagnostic and therapeutic potential of digestive endoscopy over the past few decades have notably increased the number of procedures performed, to the point that endoscopy is now almost considered to be routine. Changes in the epidemiology of colorectal cancer (CRC), which now represents the second leading cause of cancer-related death in America [1] and Europe [2], have also contributed to an increase in colonoscopies, since this procedure is considered the most accurate and effective method for early detection and prevention of CRC and premalignant precursor lesions. Colonoscopic removal of adenomatous polyps was proven to prevent approximately $80 \%$ of CRCs [3, 4], and to lower the overall death rate from the disease [5]. In this context, several studies have reported that CRC screening is clinically useful [6] and cost-effective [7] in the average-risk population, significantly reducing mortality [8].

Obesity is a well-accepted risk factor for CRC $[9,10]$; excessive body mass index (BMI) and physical inactivity are interrelated risk factors reported to account for between a fourth and a third of CRCs [11]. BMI is associated with an increased risk of incident CRC in men of all ages and in women between the ages 50-66 [12]. Indeed, excessive BMI is a modifiable risk factor associated with increased risk of adenoma and advanced adenoma recurrence [13]; unfortunately, weight loss has no effect on this risk of recurrence.

In this context, and taking into account that obesity has reached epidemic proportions in America [14] and Europe

\footnotetext{
A. J. Lucendo $(\bowtie)$

Department of Gastroenterology, Hospital General de

Tomelloso, Vereda de Socuéllamos, s/n, 13700 Tomelloso,

Ciudad Real, Spain

e-mail: alucendo@vodafone.es
}

[15], colonoscopy in obese patients represents a challenging issue for endoscopists, with much research focusing on the special features of colonoscopy in this population. For example, while a higher waist circumference has not been associated with a difficult cecal intubation [16-18], obesity constitutes an independent predictor of inadequate bowel preparation for colonoscopy [19], although these results were not reproduced when using a sodium picosulphatebased bowel preparation [20]. Furthermore, some endoscopic techniques and maneuvers normally required during the examination, including patient repositioning and the application of abdominal pressure, are more difficult to perform on obese patients. Extra difficulty is added when changing the position of a sedated obese patient. A recent study in which abdominal compression obtained with a fitted corset facilitates colonoscopy reported that extra abdominal compression and a change of position was used less frequently in the study subjects accompanied by less procedural pain [21]. In contrast, no definite data are available on the effect of a change from standard left lateral decubitus to prone position in facilitating colonoscopy in obese patients.

This number of Digestive Diseases and Sciences includes a prospective randomized trial by Uddin and colleagues [22] which reports for the first time that starting sedated colonoscopy in prone position for male obese subjects (BMI $>30 \mathrm{~kg}$ / $\mathrm{m}^{2}$ ) significantly shortens cecal intubation times with less need for patient repositioning. Additionally, the authors reported no differences in subjects' perception of pain or their willingness to repeat the procedure when compared with obese subjects in whom the exploration was started using the standard left decubitus position. The subjects were sedated with benzodiazepines and narcotics under the endoscopist's supervision due to safety concerns; patients scheduled for deep sedation with propofol or general anesthesia were excluded. Although $18 \%$ of recruited patients had antecedents of sleep apnea, half of 
them were explored in the prone position with no complications. Despite the fact that obesity is associated with an increased frequency of sedation-related complications, nonanesthesiologist-administered propofol sedation is safe and efficient [23, 24], with exceptionally rare complications with respect to airway management. In this context, propofol sedation has also been used safely by trained professionals in obese patients undergoing advanced endoscopic procedures [25], even when explored in the prone position, as frequently occurs in endoscopic retrograde cholangiopancreatography. The prone position may actually be associated with a lower risk of obstructive apnea during sedation since the tongue is less likely to fall back. In this sense, performing the procedure with the patient in the prone position may be a non-invasive way to increase oxygenation in patients with acute respiratory distress [26]. While patients with morbid obesity have been excluded from most studies evaluating carbon dioxide $\left(\mathrm{CO}_{2}\right)$ insufflation in colonoscopy, those obese patients with a BMI $<40 \mathrm{~kg} / \mathrm{m}^{2}$ have not; thus, a recent study did not report higher levels of end-tidal $\mathrm{CO}_{2}$ or adverse respiratory events in morbidly obese subjects [27].

Even if some safety aspects regarding deep sedation administered by non-anesthesiologists in prone subjects remain unresolved, the original article included in this issue of Digestive Diseases and Sciences [22] constitutes a clear confirmation of how a simple, inexpensive, and easily reproducible measure can improve colonoscopy performance in obese patients. From these results, we should reconsider whether it is time to change patients' position towards easier, but efficient procedures.

\section{References}

1. US Cancer Statistics Working Group. United States cancer Statistics: 1999-2008 incidence and mortality web-based report. Available at: http://www.cdc.gov/uscs. Accessed November 1, 2012.

2. Ferlay J, Autier P, Boniol M, Heanue M, Colombet M, Boyle P. Estimates of the cancer incidence and mortality in Europe in 2006. Ann Oncol. 2007;18:581-592.

3. Winawer SJ, Zauber AG, Ho MN, et al. Prevention of colorectal cancer by colonoscopic polypectomy. N Engl J Med. 1993;329:1977-1981.

4. Citarda F, Tomaselly G, Capocaccia R, Barcherini S, Crespi M; Italian Multicentre Study Group. Efficacy in standard clinical practice of colonoscopic polypectomy in reducing colorectal cancer incidence. Gut. 2001;48:812-815.

5. Zauber AG, Winawer SJ, O'Brien MJ, et al. Colonoscopic polypectomy and long-term prevention of colorectal-cancer deaths. N Engl J Med. 2012;366:687-696.

6. Levin B, Lieberman DA, McFarland B, et al. Screening and surveillance for the early detection of colorectal cancer and adenomatous polyps, 2008: a joint guideline from the American Cancer Society, the US Multi-Society Task Force on Colorectal Cancer, and the American College of Radiology. Gastroenterology. 2008;134:1570-1595.

7. Heitman SJ, Hilsden RJ, Au F, Dowden S, Manns BJ. Colorectal cancer screening for average-risk North Americans: an economic evaluation. PLoS ONE. 2010;7:1000370.
8. Baxter NN, Goldwasser MA, Paszat LF, Saskin R, Urbach DR, Rabeneck L. Association of colonoscopy and death from colorectal cancer. Ann Intern Med. 2009;150:1-8.

9. Moghaddam AA, Woodward M, Huxley R. Obesity and risk of colorectal cancer: a meta-analysis of 31 studies with 70,000 events. Cancer Epidemiol Biomarkers Prev. 2007;16:2533-2547.

10. Moore LL, Bradlee ML, Singer MR, et al. BMI and waist circumference as predictors of lifetime colon cancer risk in Framingham Study adults. Int J Obes Relat Metab Disord. 2004; 28:559-567.

11. Haggar FA, Boushey RP. Colorectal cancer epidemiology: incidence, mortality, survival, and risk factors. Clin Colon Rectal Surg. 2009;22:191-197.

12. Adams KF, Leitzmann MF, Albanes D, et al. Body mass and colorectal cancer risk in the NIH-AARP cohort. Am J Epidemiol. 2007; 166:36-45.

13. Laiyemo AO, Doubeni C, Badurdeen DS, et al. Obesity, weight change, and risk of adenoma recurrence: a prospective trial. Endoscopy. 2012;44:813-818.

14. Ogden CL, Carroll ME, Kit BK, Flegal KM. Prevalence of obesity in the United States, 2009-2010. NCHS Data Brief. 2012; 82:1-8.

15. Berghöfer A, Pischon T, Reinhold T, Apovian CM, Sharma AM, Willich SN. Obesity prevalence from a European perspective: a systematic review. BMC Public Health. 2008;8:200.

16. Liang C-M, Chiu Y-C, Wu K-L, et al. Impact factors for difficult cecal intubation during colonoscopy. Surg Laparosc Endosc Percutan Tech. 2012;22:443-446.

17. Anderson JC, Messina CR, Cohn W, et al. Factors predictive of difficult colonoscopy. Gastrointest Endosc. 2001;54:558-562.

18. Hsieh YH, Kuo CS, Tseng KC, Lin HJ. Factors that predict cecal insertion time during sedated colonoscopy: the role of waist circumference. J Gastroenterol Hepatol. 2008;23:215-217.

19. Borg BB, Gupta NK, Zuckerman GR, Banerjee B, Gyawali CP. Impact of obesity on bowel preparation for colonoscopy. Clin Gastroenterol Hepatol. 2009;7:670-675.

20. Fok KC, Teoh WC, Levy RL, Turner IB. Obesity does not affect sodium picosulphate bowel preparation. Intern Med J. 2012;42: 1324-1329.

21. Toros AB, Ersoz F, Ozcan O. Does a fitted abdominal corset makes colonoscopy more tolerable? Dig Endosc. 2012;24:164-167.

22. Uddin FS, Iqbal R, Harford WV, et al. Prone positioning of obese patients for colonoscopy results in shortened cecal intubation times: a randomized trial. Dig Dis Sci. 2012. (Epub ahead of print). doi: 10.1007/s10620-012-2468-x.

23. Lucendo AJ, Olveira A, Friginal-Ruiz AB, et al. Nonanesthesiologist-administered propofol sedation for colonoscopy is safe and effective: a prospective Spanish study over 1000 consecutive exams. Eur J Gastroenterol Hepatol. 2012;24:787-792.

24. Rex DK, Deenadayalu VP, Eid E, et al. Endoscopist-directed administration of propofol: a worldwide safety experience. Gastroenterology. 2009;137:1229-1237.

25. Wani S, Azar R, Hovis CE, et al. Obesity as a risk factor for sedation-related complications during propofol-mediated sedation for advanced endoscopic procedures. Gastrointest Endosc. 2011;74:1238-1247.

26. Hale DF, Cannon JW, Batchinsky AI, et al. Prone positioning improves oxygenation in adult burn patients with severe acute respiratory distress syndrome. J Trauma Acute Care Surg. 2012;72:1634-1639.

27. Díez-Redondo P, Gil-Simón P, Alcaide-Suárez N, et al. Comparison between insufflation with air or carbon dioxide during the colonoscopy in sedated patients with propofol. Rev Esp Enferm Dig. 2012;104:411-417. 